\title{
Altitudinal variations in wing morphology of Aedes albopictus (Diptera, Culicidae) in Albania, the region where it was first recorded in Europe
}

\author{
Jorian Prudhomme ${ }^{1, a, *}$, Enkelejda Velo, ${ }^{2, a}$, Silvia Bino ${ }^{2}$, Perparim Kadriaj ${ }^{2}$, Kujtim Mersini ${ }^{3}$, Filiz Gunay ${ }^{4}$, \\ and Bulent Alten ${ }^{4}$ \\ ${ }^{1}$ UMR MIVEGEC (IRD 224 - CNRS 5290 - Université de Montpellier), 911 Avenue Agropolis, 34394 Montpellier, France \\ ${ }^{2}$ Department of Control of Infectious Diseases, Institute of Public Health, Str. "Aleksandër Moisiu" No. 80, 1010 Tirana, Albania \\ ${ }^{3}$ Southeast European Center for Surveillance and Control of Infectious Diseases (SECID), Str. "Aleksandër Moisiu" No. 80, \\ 1010 Tirana, Albania \\ ${ }^{4}$ Faculty of Science, Department of Biology, Ecology Section, Vector Ecology Research Group Laboratories, Hacettepe University, \\ 06800 Ankara, Turkey
}

Received 2 April 2019, Accepted 6 August 2019, Published online 6 September 2019

\begin{abstract}
The rapid spread and settlement of Aedes albopictus mosquitoes across at least 28 countries in Europe, as well as several countries in Asia Minor, the Middle East and Africa, has made it one of the most invasive species of all time. Even though the biology of Ae. albopictus in its native tropical environment has been documented for a long time, the biology and ecology of this species in newly colonized temperate environments remain poorly known despite its important role as a vector for about twenty arboviruses. In this context, the main goals of this work were to investigate Ae. albopictus phenotypic variations at a local scale in Albania, the country where Ae. albopictus was first recorded in Europe, and to determine if its phenotypes could be affected by altitude. Analysis of Ae. albopictus wing phenotypes was performed using a geometric morphometric approach. We observed shape and size variations among altitudinal populations of Ae. albopictus. Differences of wing phenotypes were highlighted between altitude groups for male and female mosquitoes. The phenotypic variations observed in Ae. albopictus between altitudinal groups indicated these populations are exposed to environmental and ecological pressures. These results suggest the presence of phenotypic plasticity in this species.
\end{abstract}

Key words: Aedes albopictus, Geometric morphometry, Altitudinal transect, Albania.

Résumé - Variations phénotypiques des ailes d'Aedes albopictus (Diptera, Culicidae) en fonction de l'altitude en Albanie, la région où il a été signalé pour la première fois en Europe. La propagation et l'établissement rapides du moustique Aedes albopictus dans au moins 28 pays d'Europe, ainsi que dans plusieurs pays d'Asie mineure, du Moyen-Orient et d'Afrique, en ont fait l'une des espèces les plus invasives de tous les temps. Bien que la biologie d'Ae. albopictus dans son milieu tropical naturel soit documentée depuis longtemps, la biologie et l'écologie de cette espèce dans les milieux tempérés nouvellement colonisés restent mal connues malgré son rôle important de vecteur d'une vingtaine d'arbovirus. Dans ce contexte, les principaux objectifs de ce travail étaient d'étudier les variations phénotypiques d'Ae. albopictus à l'échelle locale en Albanie, le pays où Ae. albopictus a été signalé pour la première fois en Europe, et de déterminer si ses phénotypes pourraient être affectés par l'altitude. L'analyse des phénotypes des ailes d'Ae. albopictus a été effectuée en utilisant une approche de morphométrie géométrique. Nous avons observé des variations de forme et de taille parmi les populations altitudinales d'Ae. albopictus. Des différences de phénotypes d'ailes ont été mises en évidence entre les groupes d'altitude pour les moustiques mâles et femelles. Les variations phénotypiques observées chez Ae. albopictus entre les groupes altitudinaux indiquent que ces populations sont exposées à des pressions environnementales et écologiques. Ces résultats suggèrent la présence d'une plasticité phénotypique chez cette espèce.

\footnotetext{
*Corresponding author: jorian. prudhomme@hotmail. fr
}

${ }^{\text {a }}$ These authors contributed equally to this work. 


\section{Introduction}

The rapid spread and settlement of Aedes (Stegomyia) albopictus across at least 28 countries in Europe, as well as several other countries in Asia Minor, the Middle East and Africa, has made it one of the most invasive species of all time $[9,25]$. This mosquito species is a potential vector for about twenty arboviruses, including zika, chikungunya and dengue [19]. The health challenges surrounding Aedes albopictus are therefore particularly important [21]. For example, in the past decade, its role in substantial epidemics of the chikungunya virus (CHIKV) in Italy [31] demonstrates the consequences of its ability to colonize and adapt to new environments, and especially water containers in urban sites.

Aedes albopictus is often described as a tropical mosquito species from South-East Asia but its true range extends to latitudes in the North-West of China. Indeed, this species can spend the winter in diapause and its eggs resist temperatures as low as $-5{ }^{\circ} \mathrm{C}$ [23]. In Europe, this species was reported for the first time in 1979 in Albania [1], and it is now widespread and commonly found in this country, even at high altitudes (>1200 m) [42].

Nevertheless, even though the biology of Ae. albopictus in its native tropical environment has been documented since the 1980s [21], the biology and ecology of this species in newly colonized temperate environments remain poorly known despite its vectorial importance. These environments are characterized by greater climatic variations, which can impact the mosquitoes' population dynamics.

Geometric morphometry gathers together a set of methods that allow the study of phenotypes and provides information on shape and size variations, and the relationships between these two variables [14]. The morphometric study of mosquitoes can highlight a correlation between the environment and the mosquito phenotypes [32]. For example, a previous study showed that Ae. albopictus populations from different geographical regions presented significant morphometric wing shape variations [12]. Moreover, adult mosquito size can be directly influenced by the environmental conditions they underwent during larval development [3]. Additionally, it can also be correlated with many life history traits such as fecundity [8] and longevity [47].

This is the first study in Albania using a geometric morphometric approach to investigate phenotypic variations of $A e$. albopictus populations. The main goal of this study was to understand the possible phenotypic differences of Ae. albopictus populations on an altitudinal transect.

\section{Materials and methods}

\section{Study area}

The study area was located on the Tirana-Dajti Mount in Albania $\left(19^{\circ} 55^{\prime} 51.2^{\prime \prime} \mathrm{E}, 41^{\circ} 21^{\prime} 34.5^{\prime \prime} \mathrm{N}\right)$. This region is influenced by Mediterranean climate characterized by wet winters with a rainfall average of $1297 \mathrm{~mm}$ and average monthly temperatures of $+24{ }^{\circ} \mathrm{C}$ in July and $+6{ }^{\circ} \mathrm{C}$ in January. Eggs of Ae. albopictus were collected at 16 sites across a $154-1559 \mathrm{~m}$ altitude gradient transect (Fig. 1). In order to test the altitudinal effect on Ae. albopictus wing size and shape, five sites were selected along this transect and categorized into five altitude groups (A1-A5) (Table 1). The first altitude group A1 (158 m) is an artificial, non-agricultural and green urban area located in Tirana. The second altitude group A2 $(595 \mathrm{~m})$ is rural, agricultural, non-irrigated arable land. The third altitude group A3 $(762 \mathrm{~m})$ is a mixed forest and semi-natural area. The fourth and fifth altitude groups A4 (1099 m) and A5 (1140 m), respectively, are mixed forest and semi-natural areas located on the top of the Dajti Mount close to each other (Fig. 1).

\section{Mosquito collection, identification and larval rearing}

Ae. albopictus eggs were collected weekly between May and November 2013 with ovitraps. These traps are black cylindrical vessels (height: $9 \mathrm{~cm}$; diameter: $11 \mathrm{~cm}$ ) with an overflow hole ( $7 \mathrm{~cm}$ from the base) internally lined with heavy-weight seed germination paper [43]. They contained $\sim 300 \mathrm{~mL}$ of tap-water with no attractants. Our study did not involve protected or endangered species. No specific permits were needed for these sites and/or activities; nevertheless, the landowner's permission was always requested before any studies were performed on their properties.

Eggs laid on germination paper were transported to the Entomology laboratory of the Institute of Public Health (Tirana, Albania). After counting, species were identified based on their size, color, surface sculpting and shape [48]. The eggs selected from the five altitude groups collected between July and October 2013 (Table 1) were hatched at the Hacettepe University VERG Lab and reared using the CAA (Centro Agricoltura Ambiente, Bologna, Italy) standard procedure for mosquito rearing $[6,29]$. Each egg paper strip was put in a $400 \mathrm{~mL}$ glass jar, filled with $350 \mathrm{~mL}$ of deionized water and $1 \mathrm{~mL}$ of hatching solution (12.5 g nutrient broth and $2.5 \mathrm{~g}$ brewer's yeast in $100 \mathrm{~mL}$ deionized water). They were put inside a climatic chamber set at $25{ }^{\circ} \mathrm{C}$ and $80 \%$ relative humidity overnight. First instar larvae were counted on the next two days after the eggs hatched, then were randomly picked from each altitude group and were transferred to $1.5 \mathrm{~L}$ of deionized water in $31 \times 20 \mathrm{~cm}$ pans, and held in a climate chamber $\left(26^{\circ} \mathrm{C} ; 60-70 \%\right.$ relative humidity; light and dark cycle of $16 \mathrm{~h}$ and $8 \mathrm{~h}$ ) to be reared to adult stage for wing geometric morphometric analysis. The rest of the larvae were terminated. Starting from the day they were picked, the larvae from each condition were given $0.5 \mathrm{mg} / \mathrm{larva}$ of diet daily until pupation. The liquid diet consisted of tuna meal (TM, 50\% w:v), bovine liver powder (BLP, 36\% w:v), and inactivated brewer's yeast (BY, 14\% w:v) with added multiple vitamins (VM, $0.2 \mathrm{mg}$ VM by $100 \mathrm{~mL}$ of diet) [6]. Pupae were transferred to $200 \mathrm{~mL}$ plastic cups filled with deionized water. Finally, emerging adults were transferred individually into labelled $1.5 \mathrm{~mL}$ Eppendorf tubes containing $96 \%$ ethanol.

\section{Wing preparation}

For the geometric morphometric analysis, a total of 268 Ae. albopictus wings were used (111 females and 157 males) 


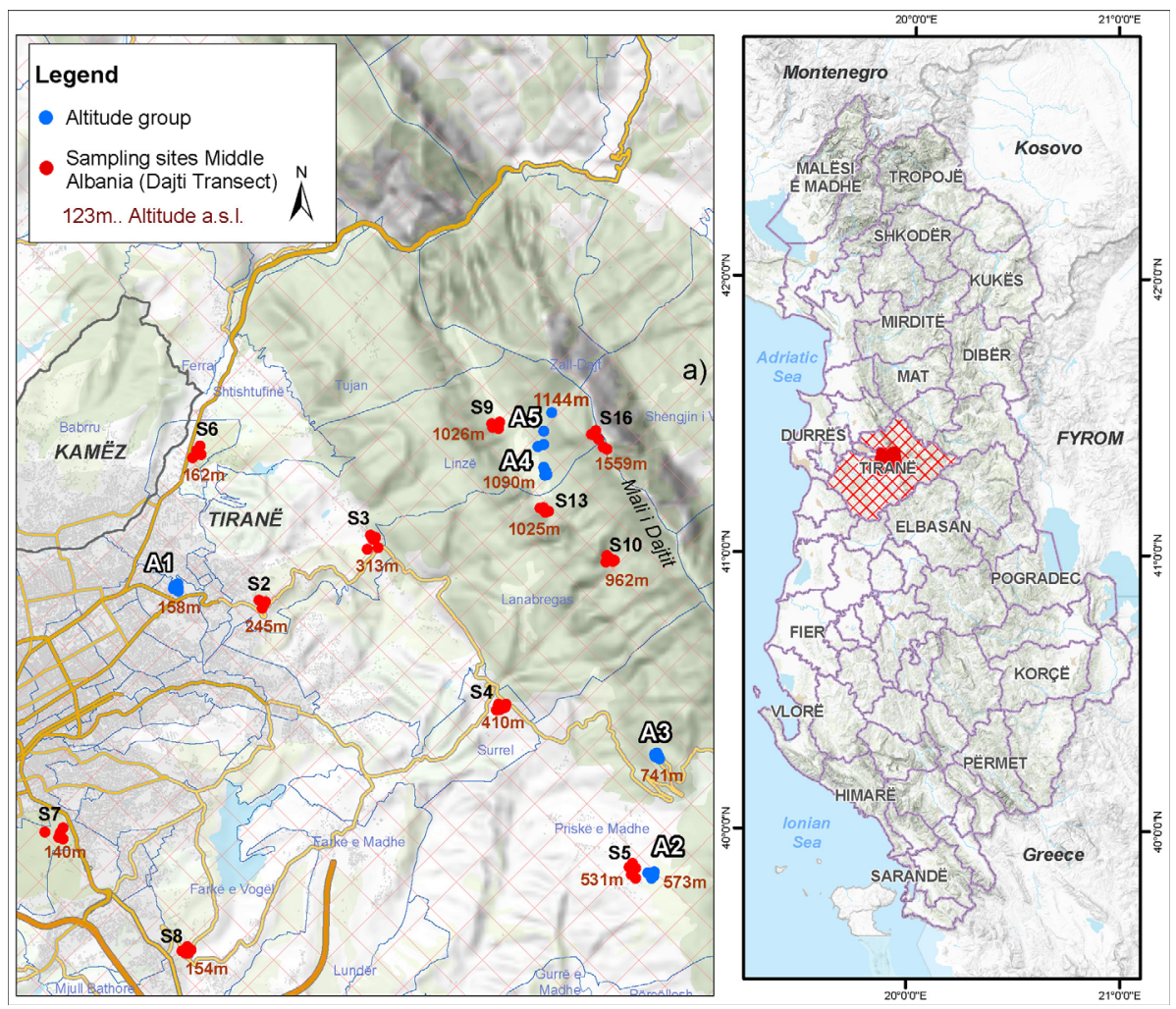

Figure 1. Map of the study area. Blue circles: altitude groups, red circles: sampling sites.

Table 1. Description of the sampling stations in our study area and number of Aedes albopictus wings analyzed by station for the geometric morphometric analysis.

\begin{tabular}{|c|c|c|c|c|c|c|c|c|}
\hline \multirow[t]{2}{*}{ Altitude group } & \multirow[t]{2}{*}{ District } & \multicolumn{2}{|c|}{ Coordinates } & \multirow[t]{2}{*}{ Altitude (m) } & \multirow[t]{2}{*}{ Biotope } & \multicolumn{3}{|c|}{$\begin{array}{l}\text { Number of wings by } \\
\text { gender }\end{array}$} \\
\hline & & North & East & & & q & $\hat{0}$ & Total \\
\hline$\overline{\mathrm{A} 1}$ & Tirana & 41.34705 & 19.85103 & 158 & Urban area & 25 & 10 & 35 \\
\hline A2 & Priske, Tirana & 41.31072 & 19.93309 & 595 & Rural area & 5 & 20 & 25 \\
\hline A3 & Dajt, Tirana & 41.32607 & 19.93374 & 762 & Forest & 44 & 70 & 114 \\
\hline A4 & Dajt, Tirana & 41.36240 & 19.91402 & 1099 & Forest & 37 & 18 & 55 \\
\hline A5 & Dajt, Tirana & 41.36663 & 19.91371 & 1140 & Forest & 0 & 39 & 39 \\
\hline Total & & & & & & 111 & 157 & 268 \\
\hline
\end{tabular}

+, female; $\widehat{\jmath}$, male.

(Table 1). Wings were shaved by friction in a $50 \%$ ethanol solution, fixed on microscopic labeled slides with Euparal and flattened under cover slips. The wing slides were photographed with a scale, then digitized, archived and analyzed.

\section{Morphometric analysis}

First, we entered the scale pictures into tps-Util 1.60 [36]. For the analysis, we then used 20 landmarks [24] following the method of Rohlf and Slice [37] using tpsDIG2 2.18 software [35]. The intersections of wing veins with the wing margin, cross veins and major veins were used as locations for landmarks (Fig. 2). Morphometric analyses and graphical outputs were performed using various modules of the CLIC software [15]. Centroid sizes are described as the square root of the sum of squared distances of a set of landmarks from their centroid, i.e. the square root of the sum of the variances of the landmarks around that centroid in $x$ - and $y$ - directions [10]. They were used as a size estimator and compared with R 3.1.2 [41] using a Kruskal-Wallis test or nonparametric Wilcoxon-Mann-Whitney test followed by a post-hoc test (Mann-Whitney tests with Bonferroni correction). In order to calculate partial warps (shape variables), landmark configurations were scaled, translated, and rotated against the consensus configuration using the GLS Procrustes superimposition 


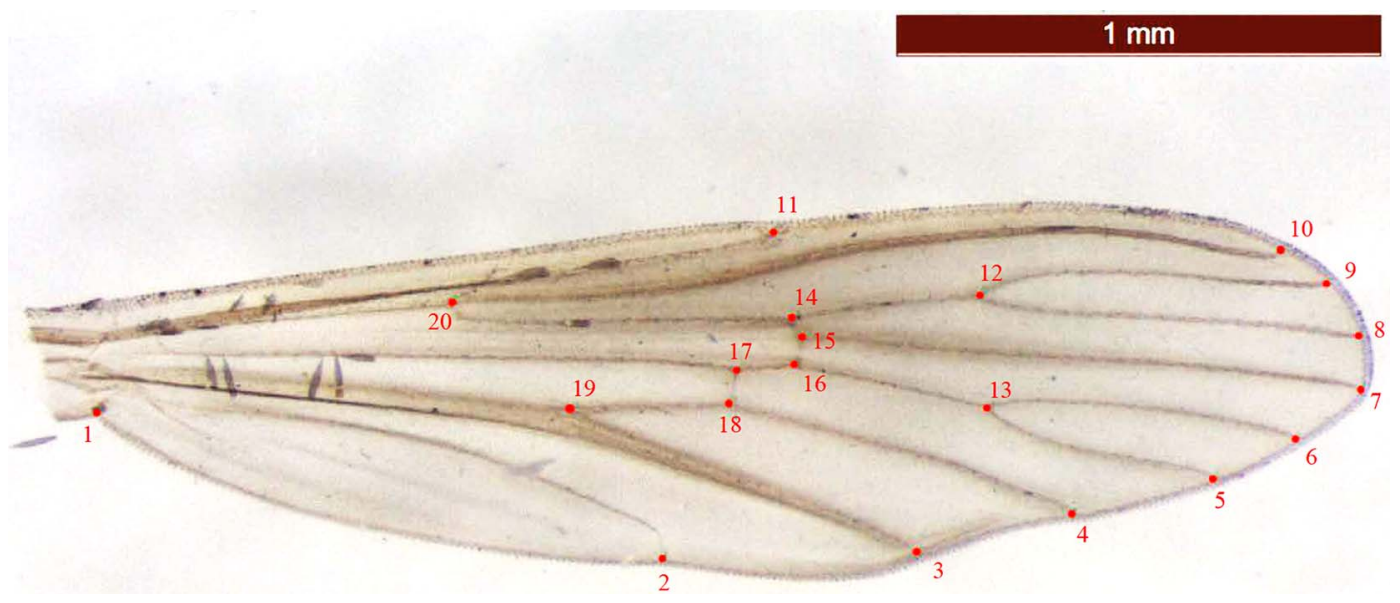

Figure 2. Example of an Aedes albopictus wing used for the geometric morphometric analysis. Red circles: landmarks.

method [2, 10, 33, 34]. To compare population samples, we used the principal components (PC), which are based on the partial warps [10]. Pairwise distances of Mahalanobis between populations were calculated with CLIC [15] and tested by nonparametric permutation tests (1000 iterations) in order to evaluate the degree of similarity between populations. The percentage of correctly assigned individuals to the corresponding group was assessed by a simple reclassification test for each individual using Mahalanobis distances. These distances were then used to construct a UPGMA tree to examine the similarities among populations with PAST (version 3.25) [20]. The thin-plate spline was computed using the software MorphoJ (version 1.07) [22] in order to visualize the shape changes in the wings between the groups tested [49]. The contribution of size to wing shape (residual allometry) was estimated by multivariate regression of partial warps on size. Finally, the presence of isolation by distance was researched using a Mantel test (correlation between Procruste values and geographical distances in meter) under PAST (version 3.25).

Analyses were performed by altitude groups. It was not possible to test the effect of month on wing morphometry because of the small number of specimens captured each month.

\section{Results}

\section{Sexual dimorphism}

Distances of Mahalanobis were significantly different between both genders (Adjusted $p$-values $<0.0001$ ) highlighting the wing shape variations between males and females (Supplementary Table S1). The observed differentiation between the two groups was supported by the simple reclassification scores (98\% for females and $100 \%$ for males). Centroid sizes, used as the wing size measure, were significantly different between genders (Wilcoxon-Mann-Whitney Test: $p$-value $<0.0001$ ), with males revealing smaller wings than females (Supplementary Fig. S1). The size contribution to wing shape differentiation was $61 \%$ (Supplementary Fig. S2).
Analyses were performed separately for males and females because phenotypic differences were found between sexes.

\section{Altitudinal differentiation for females}

As previously mentioned, the effect of altitude on Ae. albopictus phenotypes was tested separately by gender (see the sample size in Table 1). For females, wing shapes studied by distances of Mahalanobis were significantly different between all groups of altitude, except between groups A1 and $\mathrm{A} 2$ and between groups A 2 and A3 (adjusted $p$-value $<0.00833$, four components, $63.45 \%$ of total shape variance) (Fig. 3 and Supplementary Fig. S3). The observed differentiation between samples was supported by the simple reclassification scores with an average for altitudinal groups of 93.75\% (88-100). The UPGMA tree showed similar results. Population A4 segregated into a single branch (100 bootstrap value, high dissimilarity) and other populations (A1-A3) were on the second branch (53 and 58 bootstrap value) (Fig. 4).

We also observed a significant altitudinal effect on wing size (centroid size) for females $\left(\chi^{2}=52.508, p\right.$-value $\left.<0.0001\right)$. The post-hoc test highlighted significant differences between all groups except between A2 and A3 ( $p$-value $=0.4007$ ) (Fig. 5). The size contribution to wing shape differentiation was $0 \%$ and $1 \%$ (Fig. 6). Group A5 (1140 m) was not represented for females since no wings were available for this altitude (Table 1).

The Mantel test highlighted a weak and non-significant correlation between Procrustes values and geographical distance $\left(r^{2}=0.16209, p\right.$-value $\left.=0.3003\right)$.

\section{Altitudinal differentiation for males}

For males, Mahalanobis distances were significantly different between all altitudinal groups (Adjusted $p$-value $<0.005$, nine components, $83.98 \%$ of total shape variance) (Fig. 7 and Supplementary Fig. S3). The observed differentiation between samples was supported by the UPGMA tree (Fig. 8) and the simple reclassification scores with an average of $89 \%$ for altitudinal groups (81-100\%). 

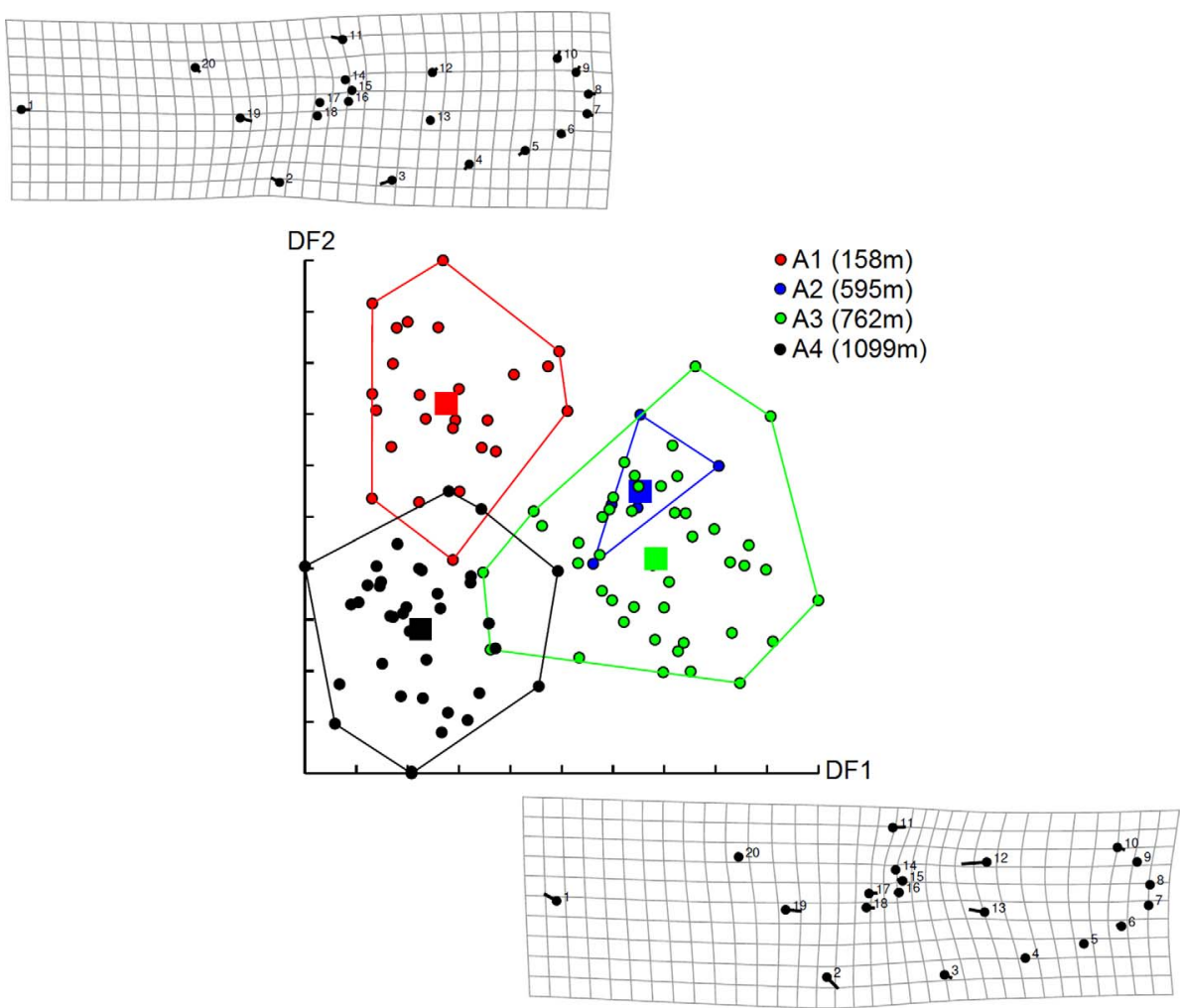

Figure 3. Distribution of Aedes albopictus females along the first two discriminant factors (DF) of shape analysis by altitude groups. This distribution was based on the partial warps. Horizontal axis: discriminant factor 1; Vertical axis: discriminant factor 2. Altitude groups: A1 (158 m), A2 (595 m), A3 (762 m), A4 (1099 m). Signs indicate each individual.

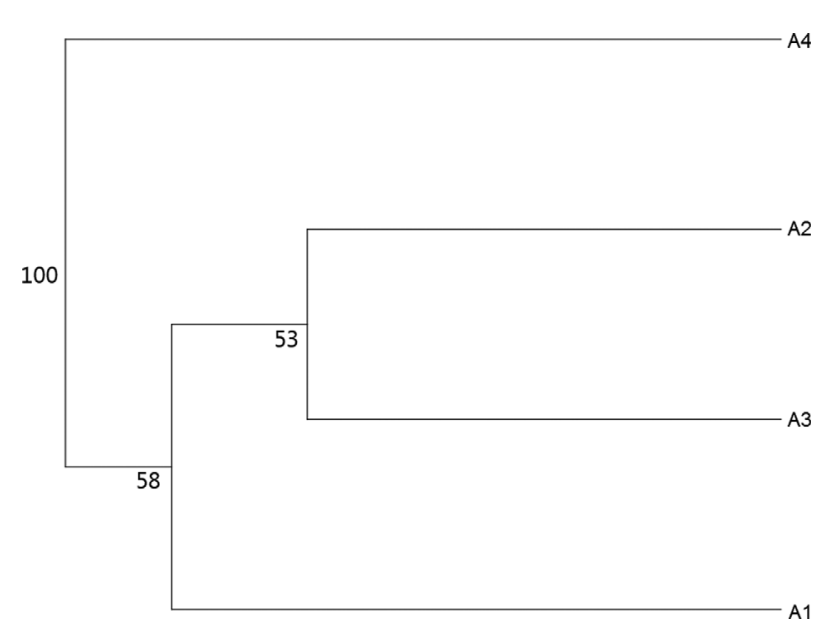

Figure 4. UPGMA tree for Aedes albopictus females based on Mahalanobis distances with 1000 bootstrap replicates. Altitude groups: A1 (158 m), A2 (595 m), A3 (762 m), A4 (1099 m).

We also observed a significant altitudinal effect on wing size (centroid size) for males $\left(\chi^{2}=55.521, p\right.$-value $\left.<0.0001\right)$. The post-hoc test highlighted significant differences between all groups, except A1 and A3 ( $p$-value = 1.0000) and between A2 and A5 ( $p$-value $=0.9805)($ Fig. 9). The size contribution to wing shape differentiation was $0 \%$ and $0 \%$ (Fig. 10).



Figure 5. Boxplot of female centroid sizes by altitude groups. Altitude groups: A1 (158 m), A2 (595 m), A3 (762 m), A4 (1099 m).

As for females, the Mantel test showed a weak and nonsignificant correlation between Procrustes values and geographical distance $\left(r^{2}=0.09096, p\right.$-value $\left.=0.7810\right)$.

\section{Discussion}

This work is the first comparative geometric morphometric study of different Ae. albopictus populations in Albania. 

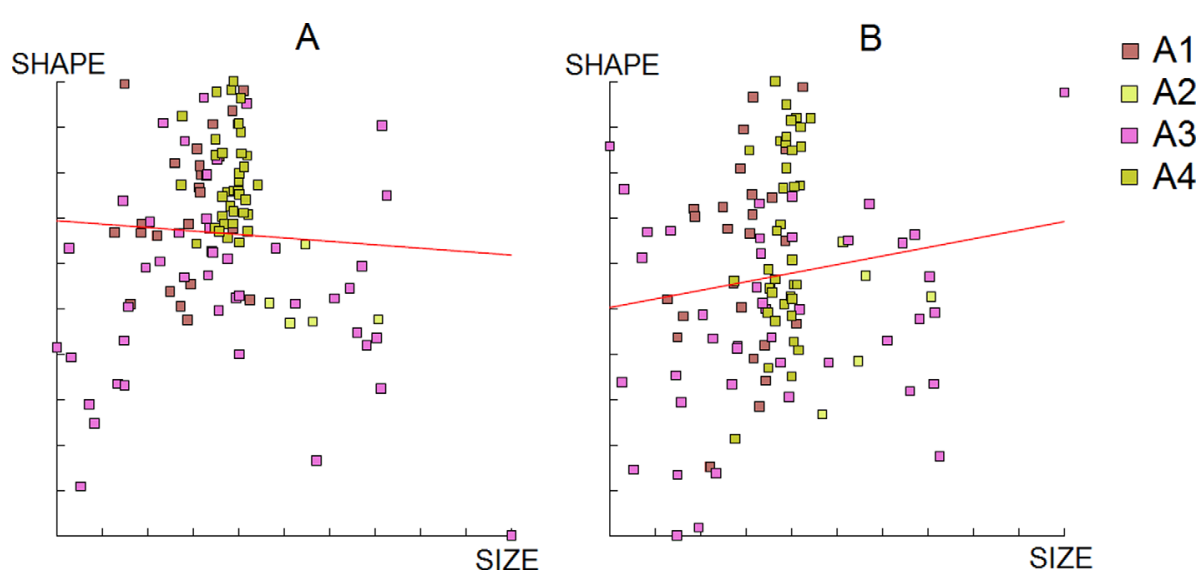

Figure 6. Regression of the first two discriminant factors (DF) of shape analysis on centroid size from Aedes albopictus females. Horizontal axis: centroid size of the wing; Vertical axis (A): discriminant factor 1, representing $24 \%$ of the total discrimination; Vertical axis (B): discriminant factors 2, representing $17 \%$ of the total discrimination. This regression was based on the partial warps. Regression line is shown. Squares indicate individual mosquitoes. Altitude groups: A1 (158 m), A2 (595 m), A3 (762 m), A4 (1099 m).
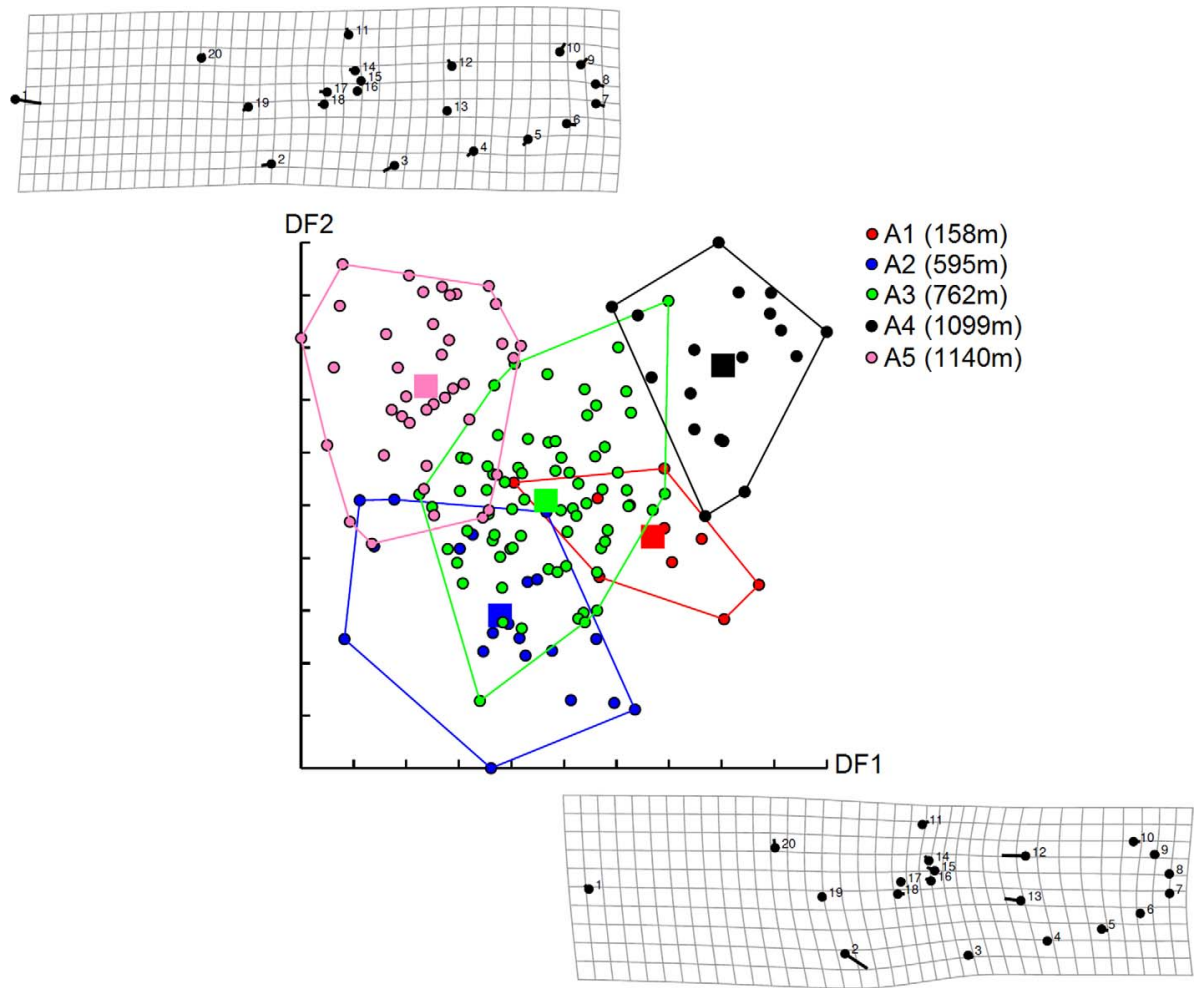

Figure 7. Distribution of Aedes albopictus males along the first two discriminant factors (DF) of shape analysis by altitude groups. This distribution was based on the partial warps. Horizontal axis: discriminant factor 1; Vertical axis: discriminant factor 2. Altitude groups: A1 (158 m), A2 (595 m), A3 (762 m), A4 (1099 m), A5 (1140 m).

To begin with, geometric morphometric analyses on the wings of specimens captured along the transect showed sexual dimorphism between males and females, a common phenomenon in many insect species [7, 16, 44, 45]. Females present longer and more slender wings compared to males (Supplementary Table S1 and Fig. S1). This dimorphism can be classically explained by the different behaviors of males and females (blood meals, egg laying, light attractiveness, etc.). For example, males might need a smaller flying capacity in comparison with females since they do not require blood meals. This difference in behavior could explain the wing differences between genders. Further studies comparing dispersion capacity according to gender are necessary to confirm this hypothesis.

Second, differences in male and female wing phenotypes (shape and size) among groups were observed. Even though this study highlights wing differences between altitudinal groups, it was not possible to draw any conclusions regarding the effect of month on the mosquito phenotypes. In the case 


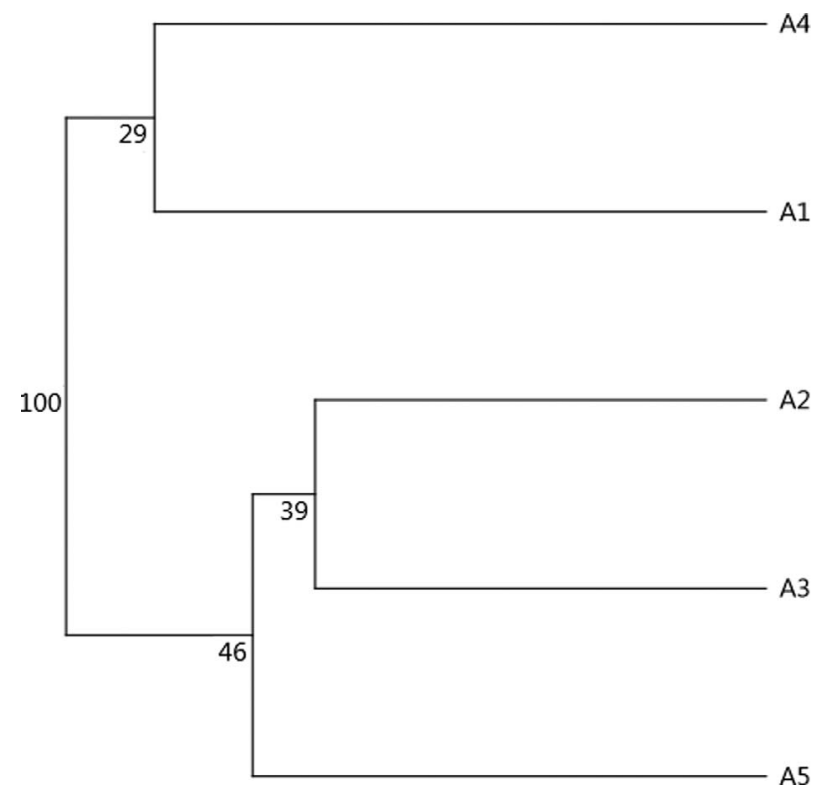

Figure 8. UPGMA tree for Aedes albopictus males based on Mahalanobis distances with 1000 bootstrap replicates. Altitude groups: A1 (158 m), A2 (595 m), A3 (762 m), A4 (1099 m), A5 $(1140 \mathrm{~m})$.

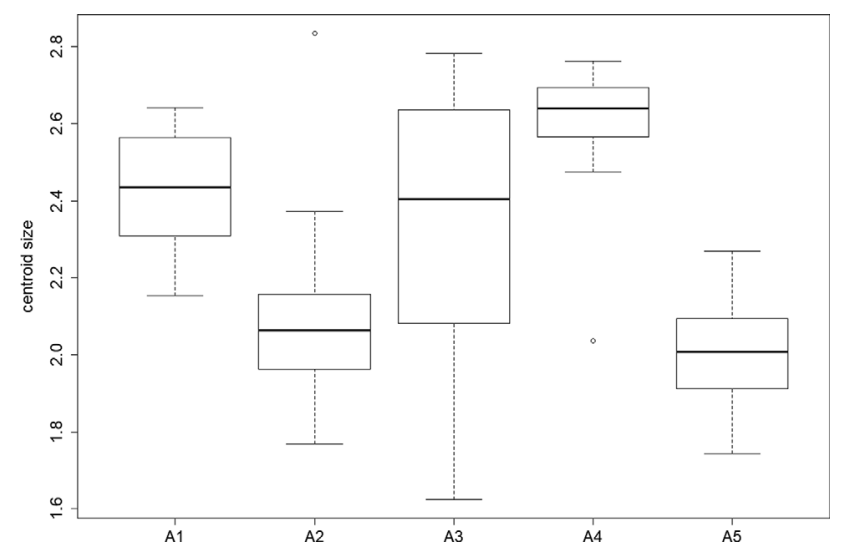

Figure 9. Boxplot of male centroid sizes by altitude groups. Altitude groups: A1 (158 m), A2 (595 m), A3 (762 m), A4 (1099 m), A5 $(1140 \mathrm{~m})$.

of small populations or a low number of captured individuals, sampling size is limiting for discriminant analyses. Indeed, the variance of the dataset cannot be explained due to the low number of principal components. Climatic and environmental conditions (temperature, relative humidity, variation between night and day, etc.) could exist depending on the month. Further studies should be considered with larger sample sizes according to month and altitude.

For males and females, the size and shape analysis indicated significant differences among altitudinal populations. This result is most probably associated with biological [18] and/or environmental factors such as different blood sources (different host populations available between stations), ecological factors like different microhabitats [27], ecosystem vegetation [13], and/or climatic effects such as temperature differences between altitudes groups [11, 26, 28].

Mosquito size can be directly influenced by environmental conditions undergone during larval development [3]. Individuals reared at higher temperatures are expected to have smaller wings $[28,30]$. A previous study carried out in the same area already showed that altitude can be a proxy for temperature, which may impact the oviposition activity of Ae. albopictus [42]. Therefore, it is very likely that their egg stages have been subjected to different climatic conditions, generating phenotypic polymorphism in adults. It is known that climatic parameters influence the development of insect larvae and therefore the phenotype of the adult [3]. In particular, temperatures will greatly influence adult size, smaller adults emerge at high temperatures and larger adults at low temperatures [4]. Indeed, low temperatures will involve slow development and therefore large individuals. Our results highlight the presence of size differences between altitude groups with, at higher altitudes, females showing larger wings. Surprisingly, this association is not observed for the males from group A4 at $1099 \mathrm{~m}$. These results associated with the presence of a sexual dimorphism reinforce the existence of gender-specific selection pressure. We also observed that group A1 (158 m) insects display larger wings than expected at low altitude. This station capture was located in the urban area of Tirana where the population of Ae. albopictus is more dense compared to higher altitudes. Larvae in the urban breeding sites might be under density and/or competition pressure or other factors related to city conditions. For example, a study showed that water containing more plant material accelerates Ae. albopictus larvae development [13]. The fact that less plant material might be present in urban breeding sites could also lead to longer development and therefore larger adults.

It is known that mosquito body size is correlated with numerous factors (ecological, environmental, physiological and genetic factors) $[3,38]$ and can be directly influenced by the environmental conditions undergone during larval development such as habitat quality [40], and larvae density and competition [17]. Since no information on the breeding sites was recorded (larvae density, water composition, etc.), we cannot predict or estimate how much these variables influence the size and shape variations. The possible correlations between geographic, climatic, genetic and phenotypic differentiations should be explored in specific and multidisciplinary studies based on larger sample sizes.

These selection pressures can also only be of environmental origin. A study [5] demonstrated for Anopheles superpictus, under laboratory conditions, the effect of temperature and humidity on wing deformation. These deformations can therefore also be explained by the variability of climatic conditions related to altitude and stations.

In addition, like many temperate species, Ae. albopictus uses diapause at the egg stage to survive the low temperatures in winter and delay reproduction until favorable climatic conditions arrive. As a key environmental signal, the shortening of days will cause females to lay diapause-programmed eggs (halted development, reduced metabolism, and increased resistance) [46]. It is therefore likely that climatic conditions, at the end and beginning of diapause, might also have played a role in 

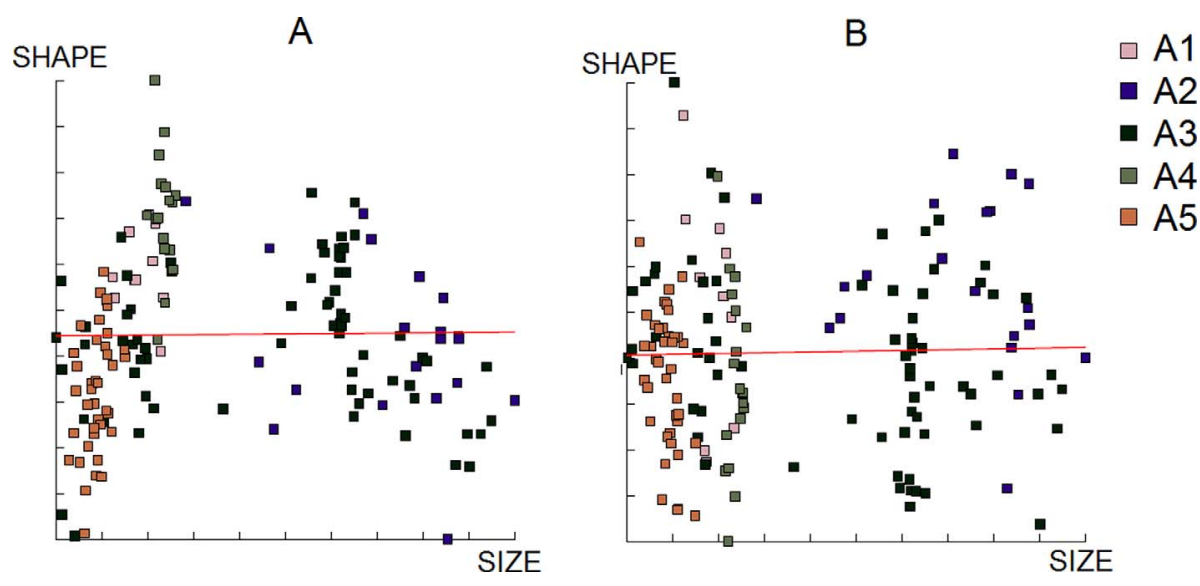

Figure 10. Regression of the first two discriminant factors (DF) of shape analysis on centroid size from Aedes albopictus males. Horizontal axis: centroid size of the wing; Vertical axis (A): discriminant factor 1, representing 19\% of the total discrimination; Vertical axis (B): discriminant factors 2 , representing $17 \%$ of the total discrimination. This regression was based on the partial warps. Regression line is shown. Squares indicate individual mosquitoes.

the phenotypic differentiation observed in adults in our study. Further studies on detailed analysis of geometric morphometric data in comparison with temperature and relative humidity data are necessary to validate, or invalidate, this hypothesis.

A previous study showed that variability in Ae. albopictus wing size between separate populations was not associated with mating success [12]. Another study suggests that there might be heterogeneity in wing morphology within Aedes aegypti populations [39]. The shape and size differences between populations can be a result of phenotypic variability. Nevertheless, additional analyses are required to test for a correlation between genetic diversity and phenotypic diversity. This could reveal differences between Ae. albopictus populations and their ability to establish themselves in different environmental and climatic conditions at different altitudes.

To conclude, this study showed different types of phenotypic variations between local populations of Ae. albopictus: sexual dimorphism and phenotype variations (shape and size of wings) according to altitude for both genders. The phenotypic variation observed between these populations appears to be correlated to the local environmental and climatic variations between altitudinal groups. These results highlight the adaptability and plasticity of this mosquito species. Further studies are necessary in order to determine whether the populations were established in those environments or if they were introduced through passive transportation during summer.

Acknowledgements. This study was funded by the EU grant FP7-261504 EDENext (http://www.edenext.eu). The contents of this publication are the sole responsibility of the authors and do not necessarily reflect the views of the European Commission. The authors are grateful to Eng. Migel Ali, GIS expert at the Geo Consulting \& Invent Albania Company, who helped us prepare the map specifically for this manuscript. We also thank the families on mount Dajti who allowed us to carry out the field work on their properties, Ada Shukullari, Erion Muhaxhiri, Elton Rogozi, and Viola Jani for their technical assistance, and Heïdi Lançon for the English revision of the manuscript.

\section{Conflict of interest}

The authors confirm that there are no known conflicts of interest associated with this publication and there has been no significant financial support for this work that could have influenced its outcome.

\section{Author contributions}

J.P., E.V. and F.G. carried out the experiments. J.P. analyzed the data. J.P., E.V., A.F. and A.M. wrote the manuscript with support from S.B and B.A. J.P., E.V., S.B. and B.A. conceived and planned the experiments. E.V., S.B., P.K. and K.M. contributed to field sampling, mosquito species identification and sample preparation.

\section{Supplementary materials}

Supplementary material is available at https://www.parasite-journal.org/10.1051/parasite/2019053/olm

Table S1. Synthesis of the Mahalanobis distance results (and $p$-values). Values below the diagonal are Mahalanobis distances (and $p$-value, adjusted $p$-value $<0.00833$ ) for Aedes albopictus females between altitude groups; values above the diagonal are Mahalanobis distances (and $p$-value, adjusted $p$-value < 0.005) for Aedes albopictus males between altitude groups; Altitude groups: A1 (158 m), A2 (595 m), A3 (762 m), A4 (1099 m), A5 (1140 m).

Fig. S1. Distribution of Aedes albopictus individuals along the first discriminant factor (DF1) of shape analysis by genders. This distribution was based on the partial warps. Black bars: females; Gray bars: males.

Fig. S2. Boxplot of centroid sizes for females and males.

Fig. S3. First discriminant factor regression on centroid size. Vertical axis: discriminant factor 1, representing $100 \%$ of the total discrimination; Horizontal axis: centroid size of the wing. The analysis was based on the partial warps. White 
squares: females; Black squares: males. Regression line is shown.

\section{References}

1. Adhami J, Reiter P. 1998. Introduction and establishment of Aedes (Stegomyia) albopictus skuse (Diptera: Culicidae) in Albania. Journal of the American Mosquito Control Association, 14(3), 340-343.

2. Alibert P, Moureau B, Dommergues J-L, David B. 2001. Differentiation at a microgeographical scale within two species of ground beetle, Carabus auronitens and $C$. nemoralis (Coleoptera, Carabidae): a geometrical approach. Zoologica Scripta, 30(4), 299-311.

3. Alto BW, Juliano SA. 2001. Precipitation and temperature effects on populations of Aedes albopictus (Diptera: Culicidae): implications for range expansion. Journal of Medical Entomology, 38(5), 646-656.

4. Aytekin A, Alten B, Caglar SS, Ozbel Y, Kaynas S, Simsek F, Kasap O, Belen A. 2007. Phenotypic variation among local populations of phlebotomine sand flies (Diptera: Psychodidae) in southern Turkey. Journal of Vector Ecology, 32(2), 226-234.

5. Aytekin S, Aytekin A, Alten B. 2009. Effect of different larval rearing temperatures on the productivity ( $\mathrm{R}$ o) and morphology of the malaria vector Anopheles superpictus Grassi (Diptera: Culicidae) using geometric morphometrics. Journal of Vector Ecology, 34(1), 32-42.

6. Balestrino F, Puggioli A, Gilles JR, Bellini R. 2014. Validation of a new larval rearing unit for Aedes albopictus (Diptera: Culicidae) mass rearing. PLoS One, 9(3), e91914.

7. Bitner-Mathá B, Klaczko L. 1999. Plasticity of Drosophila melanogaster wing morphology: effects of sex, temperature and density. Genetica, 105(2), 203-210.

8. Blackmore MS, Lord CC. 2000. The relationship between size and fecundity in Aedes albopictus. Journal of Vector Ecology, 25(2), 212-217.

9. Bonizzoni M, Gasperi G, Chen X, James AA. 2013. The invasive mosquito species Aedes albopictus: current knowledge and future perspectives. Trends in Parasitology, 29(9), 460-468.

10. Bookstein FL. 1991. Morphometric tools for landmark data. Cambridge, UK: Cambridge University Press. p. 435.

11. Briegel H, Timmermann SE. 2001. Aedes albopictus (Diptera: Culicidae): physiological aspects of development and reproduction. Journal of Medical Entomology, 38(4), 566-571.

12. Damiens D, Lebon C, Wilkinson DA, Dijoux-Millet D, Le Goff G, Bheecarry A, Gouagna LC. 2016. Cross-Mating compatibility and competitiveness among Aedes albopictus strains from distinct geographic origins - implications for future application of SIT Programs in the South West Indian Ocean Islands. PLoS One, 11(11), e0163788.

13. Darriet F. 2016. Development of Aedes aegypti and Aedes albopictus (Diptera: Culicidae) larvae feeding on the plant material contained in the water. Annals of Community Medicine and Practice, 2(1), 1014.

14. Dujardin JP. 2008. Morphometrics applied to medical entomology. Infection, Genetics and Evolution, 8(6), 875-890.

15. Dujardin JP, Slice D. 2007. Contributions of morphometrics to medical entomology, in Encyclopedia of Infectious Diseases: Modern Methodologies, Tibayrenc M, Editors. John Wiley \& Sons Inc.: Hoboken, NJ. p. 435-447.

16. Gilchrist GW, Huey RB. 2004. Plastic and genetic variation in wing loading as a function of temperature within and among parallel clines in Drosophila subobscura. Integrative and Comparative Biology, 44, 461-470.

17. Gimnig JE, Ombok M, Otieno S, Kaufman MG, Vulule JM, Walker ED. 2002. Density-dependent development of Anopheles gambiae (Diptera: Culicidae) larvae in artificial habitats. Journal of Medical Entomology, 39(1), 162-172.

18. Gojkovic N, Ludoski J, Krtinic B, Milankov V. 2019. The first molecular and phenotypic characterization of the invasive population of Aedes albopictus (Diptera: Culicidae) from the Central Balkans. Journal of Medical Entomology, pii: tjz064. DOI: $10.1093 / \mathrm{jme} / \mathrm{tjz} 064$.

19. Gratz NG. 2004. Critical review of the vector status of Aedes albopictus. Medical and Veterinary Entomology, 18(3), 215-227.

20. Hammer $\emptyset$, Harper DAT, Ryan PD. 2001. Past: Paleontological Statistics Software Package for Education and Data Analysis. Palaeontologia Electronica, 4(1), 9.

21. Hawley WA. 1988. The biology of Aedes albopictus. Journal of the American Mosquito Control Association. Supplement, 1, 1-39.

22. Klingenberg CP. 2011. MorphoJ: an integrated software package for geometric morphometrics. Molecular Ecology Resources, 11(2), 353-357.

23. Kraemer MUG, Sinka ME, Duda KA, Mylne AQN, Shearer FM, Barker CM, Moore CG, Carvalho RG, Coelho GE, Van Bortel W, Hendrickx G, Schaffner F, Elyazar IRF, Teng H-J, Brady OJ, Messina JP, Pigott DM, Scott TW, Smith DL, Wint GRW, Golding N, Hay SI. 2015. The global distribution of the arbovirus vectors Aedes aegypti and Ae. albopictus. eLife, 4, e08347.

24. Lacour G. 2016. Eco-physiological mechanisms and adaptive value of egg diapause in the invasive mosquito Aedes albopictus (Diptera: Culicidae). Belgium: Royal Belgian Institute of Natural Sciences.

25. Medlock JM, Hansford KM, Schaffner F, Versteirt V, Hendrickx G, Zeller H, Van Bortel W. 2012. A review of the invasive mosquitoes in Europe: ecology, public health risks, and control options. Vector Borne and Zoonotic Diseases, 12(6), 435-447.

26. Morales Vargas RE, Phumala-Morales $\mathrm{N}$, Tsunoda $\mathrm{T}$, Apiwathnasorn C, Dujardin JP. 2013. The phenetic structure of Aedes albopictus. Infection, Genetics and Evolution, 13, 242-251.

27. Parker AT, Gardner AM, Perez M, Allan BF, Muturi EJ. 2019. Container size alters the outcome of interspecific competition between Aedes aegypti (Diptera: Culicidae) and Aedes albopictus. Journal of Medical Entomology, 56(3), 708-715.

28. Phanitchat T, Apiwathnasorn C, Sungvornyothin S, Samung Y, Dujardin S, Dujardin JP, Sumruayphol S. 2019. Geometric morphometric analysis of the effect of temperature on wing size and shape in Aedes albopictus. Medical and Veterinary Entomology. DOI: 10.1111/mve.12385.

29. Puggioli A, Carrieri M, Dindo ML, Medici A, Lees RS, Gilles JR, Bellini R. 2017. Development of Aedes albopictus (Diptera: Culicidae) larvae under different laboratory conditions. Journal of Medical Entomology, 54(1), 142-149.

30. Ray C. 1960. The application of Bergmann's and Allen's Rules to the poikilotherms. Journal of Morphology, 106, 85-108.

31. Rezza G, Nicoletti L, Angelini R, Romi R, Finarelli AC, Panning M, Cordioli P, Fortuna C, Boros S, Magurano F, Silvi G, Angelini P, Dottori M, Ciufolini MG, Majori GC, Cassone A, group Cs. 2007. Infection with chikungunya virus in Italy: an outbreak in a temperate region. Lancet, 370(9602), 1840-1846.

32. Ricklefs RE, Miles DB. 1994. Ecological and evolutionary inferences from morphology: an ecological perspective. Ecological Morphology: Integrative Organismal Biology, 1, 13-41. 
33. Rohlf F. 1993. Relative warp analysis and an example of its application to mosquito wings, in Contributions to Morphometrics, Marcus LF, Bello Rojo E, Garcia-Valdecasas A, Editors. Museo Nacional de Ciencias Naturales: Madrid, Spain. p. 131.

34. Rohlf F. 1999. Shape statistics: Procrustes superimpositions and tangent spaces. Journal of Classification, 16, 197-223.

35. Rohlf FJ. 2015. tpsDIG2 version 2.18. Stony Brook, NY: Department of Ecology and Evolution, State University of New York.

36. Rohlf FJ. 2015. tpsUtil, file utility program. version 1.60. Stony Brook, NY: Department of Ecology and Evolution, State University of New York.

37. Rohlf FJ, Slice D. 1990. Extensions of the Procrustes method for the optimal superimposition of landmarks. Systematic Biology, 39(1), 40-59.

38. Schneider JR, Mori A, Romero-Severson J, Chadee DD, Severson DW. 2007. Investigations of dengue-2 susceptibility and body size among Aedes aegypti populations. Medical and Veterinary Entomology, 21(4), 370-376.

39. Sendaydiego JP, Torres MAJ, Demayo CG. 2013. Describing wing geometry of Aedes Aegypti using landmark-based geometric morphometrics. International Journal of Bioscience, Biochemistry and Bioinformatics, 3(4), 379-383.

40. Strickman D, Kittayapong P. 2003. Dengue and its vectors in Thailand: calculated transmission risk from total pupal counts of Aedes aegypti and association of wing-length measurements with aspects of the larval habitat. American Journal of Tropical Medicine and Hygiene, 68(2), 209-217.

41. Team RC. 2014. R: A language and environment for statistical computing. Vienna, Austria: R Foundation for Statistical Computing, 2012. ISBN 3-900051-07-0.

42. Tisseuil C, Velo E, Bino S, Kadriaj P, Mersini K, Shukullari A, Simaku A, Rogozi E, Caputo B, Ducheyne E, Della Torre A,
Reiter P, Gilbert M. 2018. Forecasting the spatial and seasonal dynamic of Aedes albopictus oviposition activity in Albania and Balkan countries. PLoS Neglected Tropical Diseases, 12(2), e0006236.

43. Velo E, Kadriaj P, Mersini K, Shukullari A, Manxhari B, Simaku A, Hoxha A, Caputo B, Bolzoni L, Rosa R, Bino S, Reiter P, della Torre A. 2016. Enhancement of Aedes albopictus collections by ovitrap and sticky adult trap. Parasites \& Vectors, 9, 223.

44. Virginio F, Vidal P, Suesdek L. 2015. Wing sexual dimorphism of pathogen-vector culicids. Parasites \& Vectors, 8(1), $159-167$.

45. Wormington JD, Juliano SA. 2014. Sexually dimorphic body size and development time plasticity in Aedes mosquitoes (Diptera: Culicidae). Evolutionary Ecology Research, 16, 223-234.

46. Xia D, Guo X, Hu T, Li L, Teng PY, Yin QQ, Luo L, Xie T, Wei YH, Yang Q, Li SK, Wang YJ, Xie Y, Li YJ, Wang CM, Yang ZC, Chen XG, Zhou XH. 2018. Photoperiodic diapause in a subtropical population of Aedes albopictus in Guangzhou, China: optimized field-laboratory-based study and statistical models for comprehensive characterization. Infectious Diseases of Poverty, 7(1), 89.

47. Xue RD, Barnard DR, Schreck CE. 1995. Influence of body size and age of Aedes albopictus on human host attack rates and the repellency of deet. Journal of the American Mosquito Control Association, 11(1), 50-53.

48. Zamburlini R, Frilli F. 2003. La corretta identificazione delle uova di Aedes albopictus. Igiene Alimenti - Disinfestazione \& Igiene Ambientale, 3(4), 8-10.

49. Zelditch ML, Swiderski DL, Sheets HD, Fink WL. 2004. Geometric morphometrics for biologists: a primer. Cambridge, MA: Academic Press.

Cite this article as: Prudhomme J, Velo E, Bino S, Kadriaj P, Mersini K, Gunay F \& Alten B. 2019. Altitudinal variations in wing morphology of Aedes albopictus (Diptera, Culicidae) in Albania, the region where it was first recorded in Europe. Parasite 26, 55.

Reviews, articles and short notes may be submitted. Fields include, but are not limited to: general, medical and veterinary parasitology; morphology, including ultrastructure; parasite systematics, including entomology, acarology, helminthology and protistology, and molecular analyses; molecular biology and biochemistry; immunology of parasitic diseases; host-parasite relationships; ecology and life history of parasites; epidemiology; therapeutics; new diagnostic tools.

All papers in Parasite are published in English. Manuscripts should have a broad interest and must not have been published or submitted elsewhere. No limit is imposed on the length of manuscripts.

Parasite (open-access) continues Parasite (print and online editions, 1994-2012) and Annales de Parasitologie Humaine et Comparée (1923-1993) and is the official journal of the Société Française de Parasitologie. 